\title{
The Diagnostic Yield of Routine
}

\section{Electrocardiography in Hypertension and Implications for Care in a Southwestern Nigerian Practice}

\author{
Olutoyin Morenike Lawal ${ }^{1,2}$ \\ Adenike Enikuomehin ${ }^{1,2}$ \\ Folajimi Otubogun (iD) 2,3 \\ 'Department of Internal Medicine, \\ University of Medical Sciences Teaching \\ Hospital Complex, Akure, Ondo State, \\ Nigeria; ${ }^{2}$ Department of Internal \\ Medicine, University of Medical Sciences, \\ Ondo, Ondo State, Nigeria; ${ }^{3}$ Department \\ of Internal Medicine, Olabisi Onabanjo \\ University Teaching Hospital, Sagamu, \\ Ogun State, Nigeria
}

Background: Nigeria, like other developing nations, has an increasing burden of hypertension. Electrocardiography is an integral part of the diagnostic work-up for the newly diagnosed hypertensive subjects. The aim of this study was to determine the diagnostic yield of electrocardiography in hypertensive patients of a southwestern Nigerian hospital.

Patients and Methods: This was a retrospective descriptive study of electrocardiographs of hypertensive patients over a six-year period. Electrographic variables of interest were cardiac rhythm and rate, left ventricular hypertrophy (LVH), left atrial enlargement (LAE), T wave abnormalities, cardiac axis, blocks, complexes, QT segment abnormalities, atrial fibrillation (AF)/flutter, supraventricular tachycardia and pre-excitation syndrome. The Pearson's chi square was used to test for differences across age groups (15-44yrs, 45-64yrs and >65yrs) and between male and female subjects with the significance level set at $5 \%(p<0.05)$.

Results: Hypertension was the indication for $40 \%$ of electrocardiographs completed and comprised of 3713 electrocardiograms (ECG) over a six-year period. The commonest abnormalities were left axis deviation (LAD) (32.2\%), LVH (20.7\%), rhythm abnormalities $(16.7 \%)$ and LAE (14.5\%). The diagnostic yield (presence of at least one electrographic abnormality) was $51 \%$ in $15-44$ yrs age group, $64 \%$ in middle aged and $76.5 \%$ in the $>65$ yrs age group. While the male subjects in this study had a slightly increased likelihood of having an abnormal finding (odds ratio 1.18: 95\% CI 1.02-1.35), the odds ratio for an abnormal ECG in subjects younger than 45 years was 0.48 (95\% CI $0.41-0.57$ ).

Conclusion: The diagnostic yield of electrocardiography in this study was considerable, although lowest in subjects younger than 45 years and increased with age. This may reflect an increased burden and earlier onset of hypertension and its complications. This should also engender prompt and aggressive management of hypertension, especially in the elderly in whom the cardiovascular complications from hypertension is most severe.

Keywords: electrocardiography, hypertension, Nigeria

\section{Introduction}

Hypertension presents a growing and significant public health challenge, being a primary contributor to heart and kidney diseases, stroke and premature death. ${ }^{1-3}$ It is estimated that over a billion people in the world have hypertension with two-thirds living in low and middle income countries (LMIC). This figure has been projected to expand further by $29 \%$ by the year 2025 with the majority of this increase expected to be driven by the developing nations. ${ }^{3}$
Correspondence: Folajimi Otubogun Department of Internal Medicine, Olabisi Onabanjo University Teaching Hospital,

Sagamu, Ogun State, Nigeria

$\mathrm{Tel}+2348062396767$

Email folabogun@gmail.com 
Yet these LMICs like Nigeria, have limited availability and affordability of diagnostic and therapeutic services. ${ }^{4,5}$ Hence there is often a pragmatic need for the critical evaluation of routine medical interventions and investigations for their roles in clinical decision making. One of the routine tests recommended in the evaluation of the hypertensive patient is the electrocardiogram (ECG), a simple, noninvasive, largely accessible and relatively inexpensive electrophysiological test that evaluates cardiac function. ${ }^{6}$ Its low sensitivity for the detection of left ventricular hypertrophy (LVH) has been described, ${ }^{7}$ yet it remains an important guide for risk stratification in hypertension.

The aim of this study was to determine the diagnostic yield of a routine ECG in subjects with hypertension seen at the cardiac electrophysiology unit at the University of Medical Sciences Teaching Hospital Complex, Akure, over a six-year period.

\section{Patients and Methods}

A six-year study of the ECGs performed in the cardiac electrophysiology unit of University of Medical Sciences Teaching Hospital Complex, Akure, Ondo state (formerly State specialist hospital, Akure) was conducted. This unit is the major electrocardiography services provider to a population of about 642,000 people residing in Akure, the capital city of oil and cocoa-rich Ondo state, southwest Nigeria. The unit made use of a General Electric MAC 5500 HD electrocardiography machine.

Anonymized data were extracted from the cardiac electrophysiology records and were collated into a spreadsheet. Demographic variables such as age and gender, referral, indication for ECG and medical diagnoses were retrieved. Electrocardiographic variables included the cardiac rhythm and rate, LVH, left atrial enlargement (LAE), T wave abnormalities, cardiac axis, blocks, complexes, QT segment abnormalities, atrial fibrillation (AF)/ flutter, supraventricular tachycardia and pre-excitation syndrome.

LVH was evaluated using the Cornell's criteria ( $\mathrm{R}$ wave in aVL $+\mathrm{S}$ wave in $\mathrm{V} 3>28 \mathrm{~mm}$ in males and $>20 \mathrm{~mm}$ in females), the Sokolow Lyon criteria (SV1 + $\mathrm{R}$ in V5 or V6 $>35 \mathrm{~mm}$ ) or Framingham criteria (R aVL> $11 \mathrm{~mm}, \mathrm{R}$ V4-V6 $>25 \mathrm{~mm})^{8}{ }^{8}$

ECG LAE was defined by any one of the following: $\mathrm{P}$ wave in any lead $>0.11 \mathrm{~s}$, notched $\mathrm{P}$ wave with interpeak duration $>0.04 \mathrm{~s}$ ( $\mathrm{P}$ mitrale) and area of negative P terminal force in lead V1 (NPTF-V1) $>0.04 \mathrm{~s} \cdot \mathrm{mm} .{ }^{9}$
A composite score was also derived to primarily assess the presence and severity of ECG abnormalities in this cohort of hypertensive patients and secondarily, to determine the diagnostic yield. Twelve ECG parameters were assigned a score of 0 and 1 for normal and abnormal finding respectively, thus each ECG entry had a minimum score of 0 and a maximum score of 12 .

\section{Statistical Analysis}

Data was analyzed with SPSS version 20. Sociodemographic and electrocardiographic variables of interest were presented as frequencies and percentages. The Pearson's chi square was used to test for differences across age groups (15-45 yrs, $45-64$ yrs and $>65 \mathrm{yrs})$ and between male and female subjects with the significance level set at $5 \%(p<0.05)$.

\section{Results}

A total of 8029 ECGS were carried out over the six-year period, of which 3713 ECGs (40.7\%) were completed in individuals with a medical diagnosis of hypertension. The majority of the ECGs in hypertensive subjects were conducted in females (62.4\%) and in individuals within 45-64 years $(52.4 \%)$ (Table 1$)$.

The commonest abnormality in this study was axis deviation, being present in about a third of all ECGs and comprised predominantly by left axis deviation (LAD) (Table 2). Male sex and age $\geq 45$ years were associated with LAD.

Voltage criteria for LVH was met in only a fifth of ECGs, least prevalent in the young, intermediate in the middle aged and most prevalent in the elderly.

There was also a similar and significant increment in prevalence of electrocardiographic LAE with age. There was a $16.7 \%$ prevalence of sinus arrhythmia, significantly higher in females (18.8 females: $13.2 \%$ males) but with no significant differences across age groups.

Abnormal heart rate was present in $13.7 \%$ of the study population. Female subjects had the highest proportion of

Table I Study Population

\begin{tabular}{|l|r|r|r|}
\hline Age Groups & Male $\mathbf{n}(\%)$ & Female $\mathbf{n}(\%)$ & \\
\hline$\leq 45 y r s$ & $302(38.4)$ & $481(61.6)$ & $783(21.0)$ \\
\hline $45-64$ & $703(36.0)$ & $1244(64.0)$ & $1947(52.4)$ \\
\hline$\geq 65 y r s$ & $392(40.2)$ & $591(59.8)$ & $983(26.4)$ \\
\hline All & $1397(37.6)$ & $2316(62.4)$ & $3713(100)$ \\
\hline
\end{tabular}


Table 2 ECG Abnormalities by Sex and Age

\begin{tabular}{|c|c|c|c|c|c|c|c|c|c|}
\hline \multicolumn{2}{|l|}{ ECG Parameters } & \multirow{2}{*}{$\begin{array}{l}\begin{array}{l}\text { Males } \\
\text { n(\%) }\end{array} \\
9(0.6)\end{array}$} & \multirow{2}{*}{$\begin{array}{l}\begin{array}{l}\text { Females } \\
\text { n(\%) }\end{array} \\
16(0.7)\end{array}$} & \multirow{3}{*}{$\begin{array}{r}\text { p value } \\
0.96\end{array}$} & \multirow{2}{*}{$\begin{array}{l}\begin{array}{l}\leq \mathbf{4 5 y r s} \\
\mathrm{n}(\%)\end{array} \\
\mathrm{I}(0.1)\end{array}$} & \multirow{2}{*}{$\begin{array}{l}\begin{array}{l}\text { 45-64yrs } \\
\text { n(\%) }\end{array} \\
5(0.2)\end{array}$} & \multirow{2}{*}{$\begin{array}{l}\begin{array}{l}\geq 65 y r s \\
\text { n(\%) }\end{array} \\
19(1.6)\end{array}$} & \multirow{2}{*}{$\begin{array}{r}\text { p value } \\
0.001\end{array}$} & \multirow{2}{*}{$\begin{array}{l}\begin{array}{l}\text { Total } \\
\text { n(\%) }\end{array} \\
25(0.7)\end{array}$} \\
\hline Atrial fibrillation/ & Fibrillation & & & & & & & & \\
\hline Tiutter & Flutter & $2(0.1)$ & $4(0.1)$ & & $0(0)$ & $4(0.2)$ & $2(0.2)$ & & $6(0.2)$ \\
\hline \multirow[t]{2}{*}{ Abnormal axis } & LAD & $512(36.8)$ & $685(29.6)$ & \multirow[t]{2}{*}{0.001} & $115(14.7)$ & $648(33.3)$ & $433(44.5)$ & \multirow[t]{2}{*}{0.001} & $1197(32.2)$ \\
\hline & RAD & $7(0.5)$ & $10(0.4)$ & & $3(0.3)$ & $7(0.3)$ & $7(0.7)$ & & $17(0.5)$ \\
\hline \multirow[t]{6}{*}{ Blocks } & Ist AVB & $46(3.3)$ & $29(1.3)$ & & $9(1.1)$ & $35(1.8)$ & $30(3.0)$ & & $75(2.0)$ \\
\hline & 2nd AVB & $I(0.1)$ & $2(0.1)$ & & $0(0)$ & $\mathrm{I}(0.5)$ & $2(0.2)$ & & $3(0.1)$ \\
\hline & $3 r d A V B$ & $I(0.1)$ & $0(0)$ & & 0 & 0 & $\mathrm{I}(0 . \mathrm{I})$ & & $I(0.0)$ \\
\hline & RBBB & $32(2.3)$ & $42(1.8)$ & & $6(0.7)$ & $38(1.9)$ & $30(3.0)$ & & $74(2.0)$ \\
\hline & LBBB & $10(0.7)$ & $18(0.8)$ & & $I(0.1)$ & $7(0.36)$ & $19(1.9)$ & & $28(0.8)$ \\
\hline & LAFB & $103(7.4)$ & $73(3.2)$ & & $8(1.0)$ & $86(4.4)$ & $82(8.4)$ & & 176(4.8) \\
\hline \multirow[t]{2}{*}{ Complexes } & Atrial & $43(3.1)$ & $46(2.0)$ & \multirow[t]{2}{*}{0.045} & $7(0.8)$ & $25(1.2)$ & $57(5.8)$ & \multirow[t]{2}{*}{0.001} & $89(2.4)$ \\
\hline & Ventricular & $50(3.6)$ & $66(2.9)$ & & $7(0.8)$ & $46(2.3)$ & $63(6.4)$ & & $116(3.1)$ \\
\hline \multicolumn{2}{|l|}{ LAE } & $23 I(16.6)$ & $305(\mid 3.2)$ & 0.004 & $77(9.8)$ & $291(14.9)$ & $168(17.2)$ & 0.001 & $536(\mid 4.5)$ \\
\hline \multicolumn{2}{|l|}{ LVH } & $293(21.0)$ & $473(20.4)$ & 0.671 & II4(I4.5) & $40 \mathrm{I}(20.6)$ & $251(25.8)$ & 0.001 & $766(20.7)$ \\
\hline \multicolumn{2}{|l|}{ WPW } & $5(0.4)$ & $2(0.1)$ & 0.064 & $I(0.1)$ & $2(0.1)$ & $4(0.4)$ & 0.324 & $7(0.2)$ \\
\hline \multicolumn{2}{|l|}{ SVT } & $13(0.9)$ & $21(0.9)$ & 0.937 & $5(0.6)$ & $16(0.8)$ & $13(1.3)$ & 0.431 & $34(0.9)$ \\
\hline \multirow{2}{*}{$\begin{array}{l}\text { QT segment } \\
\text { anomalies }\end{array}$} & Long & $4 I(2.9)$ & $98(4.2)$ & 0.006 & $23(2.9)$ & $8 I(4.1)$ & $35(3.6)$ & 0.768 & $139(3.8)$ \\
\hline & Short & $7(0.5)$ & $2(0.1)$ & & $I(0.1)$ & $6(0.3)$ & $2(0.2)$ & & $9(0.2)$ \\
\hline \multirow[t]{2}{*}{ Rate disorders } & Tachycardia & $122(8.8)$ & $343(14.8)$ & \multirow[t]{2}{*}{0.001} & $125(\mid 5.9)$ & $246(12.6)$ & $93(9.5)$ & \multirow[t]{2}{*}{0.004} & $465(12.6)$ \\
\hline & Bradycardia & $20(1.4)$ & $19(0.8)$ & & $10(1.2)$ & $18(0.9)$ & $\mathrm{II}(\mathrm{I} . \mathrm{I})$ & & $39(1.1)$ \\
\hline \multicolumn{2}{|l|}{ Rhythm disorders } & $184(13.2)$ & $436(18.8)$ & 0.001 & $\mid 48(\mid 8.9)$ & $309(15.8)$ & $162(16.6)$ & 0.169 & $620(16.7)$ \\
\hline \multirow[t]{3}{*}{ T wave anomalies } & Inferior & $29(2.1)$ & $33(1.4)$ & \multirow[t]{3}{*}{0.182} & $14(1.7)$ & $32(1.6)$ & $16(1.6)$ & \multirow[t]{3}{*}{0.015} & $62(1.7)$ \\
\hline & Lateral & $59(4.2)$ & $75(3.2)$ & & $15(1.9)$ & 63(3.2) & $55(5.6)$ & & 134(3.6) \\
\hline & Anterior & $53(3.8)$ & $91(3.9)$ & & $26(3.3)$ & $82(4.2)$ & $36(3.7)$ & & I44(3.9) \\
\hline
\end{tabular}

Abbreviations: AVB, atrioventricular blocks; LAE, left atrial enlargement; LAFB, left anterior fascicular block; BBB, left bundle branch block; LVH, left ventricular hypertrophy; PES, pre-excitation syndrome; PSVT, paroxysmal supraventricular tachycardia; RAD, right axis deviation; RBBB, right bundle branch block; SVT, supraventricular tachycardia; WPW, Wolff-Parkinson-White pre-excitation.

tachycardia (14.8\%) and the least prevalence for bradycardia $(0.8 \%)$. Tachycardia was also commonest in $<45$ years and rarest in $>65$ years.

$\mathrm{T}$ wave abnormalities were described in $9.2 \%$ of tests with inferior T-wave anomalies least prevalent. Atrial and ventricular complexes were observed in $5.5 \%$ of the study population and were rare under the age of $45 y$ years $(1.6 \%)$, intermediate in ages 45-65years (3.5\%), and commonest in subjects older than 65years $(12.2 \%)$.
Long and short QT abnormalities accounted for 3.8\% and $0.2 \%$ respectively in this cohort.

Left anterior fascicular block was present in only $4.8 \%$ of all ECGs and was twice as prevalent in males $(2.3: 1 \mathrm{M} /$ $F$ ratio) and in the elderly (8.4\%). First degree AVB and RBBB were reported in $2 \%$ of all ECGs while complete heart block was documented in only 1 subject.

Rare electrocardiographic abnormalities included paroxysmal SVT (0.9\%), AF (0.7\%), atrial flutter $(0.2 \%)$ and 
Table 3 Composite Score of ECG Abnormalities

\begin{tabular}{|l|l|l|l|r|r|}
\hline Comp. & \multicolumn{2}{|l|}{ Sex n(\%) } & \multicolumn{3}{l|}{ Age Groups n (\%) } \\
\hline Score & Male & \multicolumn{1}{l|}{ Female } & \multicolumn{1}{l|}{ 45yrs } & \multicolumn{1}{|l|}{$45-64 y r s$} & $\geq 65 y r s$ \\
\hline 0 & $462(33.2)$ & $853(36.9)$ & $383(49.0)$ & $700(36.0)$ & $228(23.5)$ \\
\hline 1 & $390(28.0)$ & $604(26.1)$ & $179(22.9)$ & $540(27.8)$ & $273(28.1)$ \\
\hline 2 & $279(20.0)$ & $459(19.9)$ & $141(18.0)$ & $366(18.8)$ & $229(23.6)$ \\
\hline 3 & $160(11.5)$ & $267(11.5)$ & $64(8.2)$ & $211(10.9)$ & $152(15.7)$ \\
\hline 4 & $72(5.2)$ & $93(4.0)$ & $13(1.7)$ & $93(4.8)$ & $59(6.1)$ \\
\hline 5 & $20(1.4)$ & $27(1.2)$ & $1(0.1)$ & $28(1.4)$ & $18(1.9)$ \\
\hline 6 & $8(0.6)$ & $6(0.3)$ & $1(0.1)$ & $5(0.3)$ & $8(0.8)$ \\
\hline 7 & $1(0.1)$ & $3(0.1)$ & 0 & 0 & $4(0.4)$ \\
\hline
\end{tabular}

WPW pattern pre-excitation $(0.2 \%)$. WPW had a male predilection (sex ratio of 4:1) while paroxysmal supraventricular tachycardia, AF and flutter had similar occurrence in both sexes. AF and WPW pattern pre-excitation in individuals older than 65 years were at least eight and four times commoner respectively than in the middle aged and the young.

About a third of all ECGs done in subjects with hypertension had no abnormality reported and four-fifths of completed tests had two or less electrocardiographic anomalies detected. Thus, less than a fifth of these tests had three or more abnormalities (Table 3).

Males had a slightly increased likelihood of having an abnormal ECG (odds ratio 1.18: 95\% CI 1.02-1.35). The odds ratio for having an abnormal ECG in subjects younger than 45 years was least but greatest for individuals 65 years or older (Table 4).

\section{Discussion}

The majority of the subjects were older than 45 years; a finding that reflects the fact that hypertension increases with advancing age. ${ }^{10}$ The female predominance in this

Table 4 Probability of an Abnormal ECG by Age Groups and Sex

\begin{tabular}{|l|l|l|l|l|}
\hline \multicolumn{2}{|l|}{ Variables } & Odds Ratio & $\mathbf{9 5 \%}$ CI & $\boldsymbol{P}$ \\
\hline \multirow{3}{*}{ Sex } & Male & 1.17 & $1.02-1.35$ & 0.022 \\
\cline { 2 - 5 } & Female & 0.84 & $0.73-0.97$ & 0.022 \\
\hline \multirow{2}{*}{ Age } & $<45 y \mathrm{yrs}$ & 0.48 & $0.41-0.56$ & 0.0001 \\
\cline { 2 - 5 } & $45-64 y r s$ & 0.94 & $0.82-1.07$ & 0.38 \\
\cline { 2 - 5 } & $\geq 65 y r s$ & 2.17 & $1.84-2.57$ & 0.0001 \\
\hline
\end{tabular}

population may be due to the general better health seeking behavior, better hypertension awareness and early identification of hypertensive disorders in pregnancy during antenatal care, as well as longer life expectancy. ${ }^{11-13}$

$\mathrm{AF}$ was an uncommon finding in this study population unlike what obtains in previous studies in which AF was observed to be the most common arrhythmia found in hypertension. ${ }^{14} \mathrm{AF}$ has been reported to be lower in Africans than people of other regions. ${ }^{15}$ A study in the USA showed that the prevalence of AF in Africans was notably lower among the African American population compared to Caucasians. ${ }^{16} \mathrm{AF}$ prevalence of $0.7 \%$ was found in Kenyans and Tanzanians. ${ }^{17,18}$ A possibility of genetic factors being responsible for the low prevalence of AF in the African population has been suggested. The population distribution of the elderly accounting for the minority of the cohort studied may also explain the lower incidence of $\mathrm{AF}$ in this study, which contrasts with the preponderance of $\mathrm{AF}$ among the elderly population in other studies. ${ }^{19}$

Axis deviation, in particular LAD, was the most frequent electrocardiographic finding in this study and a wide array of reasons have been posited for its occurrence in many hypertensive subjects. At one end is that LAD may be inconsequential, probably as a result of the left anatomic position of the heart while at the other is that it may be due significant LVH and left bundle branch block. ${ }^{20-22}$ In this study, male sex and advancing age were determinants of the LAD, an observation that has been similarly established. ${ }^{23}$

Isolated LAFB was the commonest block observed in this cohort but it has been traditionally considered a benign electrocardiographic finding in individuals without structural heart disease, commoner in males and with advancing age. ${ }^{24,25}$ However, its existence in the presence of other cardiac pathologies portends a poor prognosis. ${ }^{26}$

First degree atrioventricular block (AVB) and right bundle branch block (RBBB) were reported in $2 \%$ of all ECGs of the study population, while complete heart block was present in only one of the subjects. Researchers have documented an association between various degrees of heart block and hypertension, which was attributed to possible infiltration of the atrioventricular conduction system by fibrosis as a result of high blood pressure. ${ }^{27,28}$

Atrial and ventricular complexes were quite rare in the young $(1.6 \%)$ but relatively common in the elderly $(12.2 \%)$. Supra ventricular and ventricular ectopics are frequent findings in hypertensive subjects. ${ }^{14}$ 
$=\mathrm{LAE}$ was also shown to be of high prevalence in this cohort of subjects, being highest in subjects older than 65 years. LAE is a notable morphological adaptation found in hypertensive patients that occurs early in hypertension, influenced by age and an independent predictor of cardiovascular events. ${ }^{29-32}$

LVH was found in $20 \%$ of the study population. The sensitivity of ECG LVH is low and echocardiography together with cardiac magnetic resonance imaging (CMRI) have been shown to give better LVH yield. A study found electrocardiographic LVH of $9 \%$ in contrast to echocardiographic LVH prevalence of $32 \%$ in the same group of patients. ${ }^{33}$ Yet, electrocardiographic LVH correlates fairly well with increased cardiovascular morbidity and mortality in the hypertensive population and deserves due attention in clinical decision making. In this study the higher proportion of younger population may also contribute to the relatively low prevalence of LVH QT abnormalities, noted in this study has been demonstrated repeatedly in hypertensive patients and its significant contribution to arrhythmias and premature cardiac death has been established. ${ }^{34,35}$ QT interval is a measure of myocardial depolarization. Cardiomyocyte hypertrophy and consequent increased left ventricular mass with accompanying changes in left ventricular transmural dispersion of depolarization, changes in the tone of the autonomic nervous system of some hypertensive patients, antihypertensive medications and rarely mechano-electrical feedback are some of the possible mechanisms that has been advanced as being responsible for the QT interval alteration observed in hypertensive subjects. ${ }^{36}$

The only significant ECG abnormality that was not prevalent in the elderly was heart-rate disorder, which was most frequent in subjects younger than 45 years.

T wave abnormalities were described in the ECGs of the study group. $\mathrm{T}$ wave abnormalities in hypertensive individuals have reportedly varied widely, from nonspecific $\mathrm{T}$ wave abnormality to strain $\mathrm{T}$ wave abnormality is a marker of $\mathrm{LVH}$ and it portends poor prognosis in hypertensive patients. ${ }^{37,38}$

The diagnostic yield of ECG in the youngest age group was below $10 \%$ for most ECG abnormalities with the notable exceptions of LVH (14.5\%), abnormal rhythm (18.9\%), rate $(17.3 \%)$ and axis deviation (15\%). This may be attributable to shorter duration of hypertension and lower prevalence of hypertensive heart disease in this group.

The increased prevalence of ECG abnormalities in the elderly population may be explained by the higher prevalence and severity of hypertension in the elderly population as established by previous studies. ${ }^{11,39,40}$

The composite scores show that half of all ECGs performed on a young hypertension subject will show no abnormality in contrast to middle age and the elderly in which two-thirds and three quarters respectively of completed ECGs will have at least one electrocardiographic anomaly.

ECG is an essential investigation in hypertensive patients as ECG markers may predict sudden cardiac death, especially $\mathrm{P}$ wave duration, interatrial block, and deep terminal negativity of the $\mathrm{P}$ wave in $\mathrm{V} 1$, prolonged QT and $\mathrm{T}$ peak-T end intervals, QRS duration and between QRS and T vectors, premature ventricular contractions, and ECG hypertrophy criteria. ${ }^{41}$

\section{Strengths}

This study comprised of a large amount of ECGs and is likely to enhance its robustness and generalizability of its findings.

\section{Limitations}

This was a retrospective descriptive study that explored associations rather than causality. Also the roles of blood pressure control, medications, comorbidities such as renal disease, lifestyle factors such as smoking and lipid panels were not explored due to the retrospective nature of the study and non-inclusion of these important data in electrophysiology records of the institution.

\section{Conclusion}

The diagnostic yield of ECG in hypertension is highest in the elderly, intermediate in the middle aged and lowest in the young. These findings are likely to be linked to the duration of hypertension as well as age-related electrocardiographic changes. This increasing burden of ECG abnormalities across the age groups for hypertensive individuals calls for improved awareness of hypertension and vigorous interventions to limit the devastating cardiovascular consequences that may ensue.

\section{Statement of Ethics}

Ethical review and approval was obtained from Health Research Ethics Committee of the University of Medical Sciences, Ondo, Ondo state, Nigeria. Informed consent was not required due to the anonymized data, and this study was conducted in accordance with the Helsinki Declaration. 


\section{Author Contributions}

All authors made a significant contribution to the work reported, whether that is in the conception, study design, execution, acquisition of data, analysis and interpretation, or in all these areas; took part in drafting, revising or critically reviewing the article; gave final approval of the version to be published; have agreed on the journal to which the article has been submitted; and agree to be accountable for all aspects of the work.

\section{Disclosure}

The authors have no conflicts of interest to declare.

\section{References}

1. World Health Organisation. Hypertension; September 13, 2019. Available from: https://www.who.int/news-room/fact-sheets/detail/ hypertension. Accessed May 1, 2020.

2. Kearney PM, Whelton M, Reynolds K, Muntner P, Whelton PK, He J. Global burden of hypertension: analysis of worldwide data. Lancet. 2005;365(9455):217-223. doi:10.1016/S0140-6736(05)17741-1

3. Fisher NDL, Curfman G. Hypertension - a public health challenge of global proportions. JAMA. 2018;320(17):1757-1759. doi:10.1001/ jama.2018.16760

4. Wagner AK, Graves AJ, Reiss SK, LeCates R, Zhang F, RossDegnan D. Access to care and medicines, burden of health care expenditures, and risk protection: results from the world health survey. Health Policy (New York). 2011;100(2-3):151-158. doi:10.1016/j.healthpol.2010.08.004

5. Joshi R, Jan S, Wu Y, MacMahon S. Global inequalities in access to cardiovascular health care. our greatest challenge. $J$ Am Coll Cardiol. 2008;52(23):1817-1825. doi:10.1016/j.jacc.2008.08.049

6. Williams B, Mancia G, Spiering W, et al. 2018 Practice guidelines for the management of arterial hypertension of the European Society of Hypertension (ESH) and the European Society of Cardiology (ESC). Blood Press. 2018;27(6):314-340. doi:10.1080/08037 051.2018.1527177

7. Devereux RB, Koren MJ, De Simone G, Okin PM, Kligfield P. Methods for detection of left ventricular hypertrophy: application to hypertensive heart disease. Eur Heart J. 1993;14(suppl_D):8-15. doi:10.1093/eurheartj/14.suppl_D.8

8. Ogunlade O, Akintomide AO. Assessment of voltage criteria for left ventricular hypertrophy in adult hypertensives in south-western Nigeria. J Cardiovasc Dis Res. 2013;4(1):44-46. doi:10.1016/j. jedr.2013.02.005

9. Tsao CW, Josephson ME, Hauser TH, et al. Accuracy of electrocardiographic criteria for atrial enlargement: validation with cardiovascular magnetic resonance. J Cardiovasc Magn Reson. 2008;10(1):7. doi:10.1186/1532-429X-10-7

10. Yoon SS, Burt V, Louis T, Carroll MD. Hypertension among adults in the United States, 2009-2010. NCHS Data Brief. 2012;(107):1-8.

11. Everett B, Zajacova A. Gender differences in hypertension and hypertension awareness among young adults. Biodemography Soc Biol. 2015;61(1):1-17. doi:10.1080/19485565.2014.929488

12. Ekwunife OI, Udeogaranya PO, Nwatu IL. Prevalence, awareness, treatment and control of hypertension in a nigerian population. Health (Irvine Calif). 2010;2(7):731-735. doi:10.4236/health.2010.27111

13. Rahman M, Williams G, Al Mamun A. Gender differences in hypertension awareness, antihypertensive use and blood pressure control in Bangladeshi adults: findings from a national cross-sectional survey. $J$ Health Popul Nutr. 2017;36(1):23. doi:10.1186/s41043-017-0101-5
14. Lip GYH, Coca A, Kahan T, et al. Hypertension and cardiac arrhythmias: executive summary of a consensus document from the European Heart Rhythm Association (EHRA) and ESC Council on Hypertension, endorsed by the Heart Rhythm Society (HRS), AsiaPacific Heart Rhythm Society (APHRS), and Sociedad Latinoamericana de Estimulación Cardíaca y Electrofisiología (SOLEACE). Eur Heart J Cardiovasc Pharmacother. 2017;3 (4):235-250. doi:10.1093/ehjcvp/pvx019

15. Stambler BS, Ngunga LM. Atrial fibrillation in sub-saharan Africa: epidemiology, unmet needs, and treatment options. Int J Gen Med. 2015;8:231-242. doi:10.2147/IJGM.S84537

16. Alonso A, Agarwal SK, Soliman EZ, et al. Incidence of atrial fibrillation in whites and African-Americans: the Atherosclerosis Risk in Communities (ARIC) Study. Am Heart J. 2009;158(1):111-117. doi:10.1016/j.ahj.2009.05.010

17. Nguyen TN, Hilmer SN, Cumming RG. Review of epidemiology and management of atrial fibrillation in developing countries. Int $J$ Cardiol. 2013;167(6):2412-2420. doi:10.1016/j.ijcard.20 13.01.184

18. Dewhurst MJ, Adams PC, Gray WK, et al. Strikingly low prevalence of atrial fibrillation in elderly Tanzanians. J Am Geriatr Soc. 2012;60 (6): $1135-1140$. doi: $10.1111 / \mathrm{j} .1532-5415.2012 .03963 . x$

19. Díez-Villanueva P, Alfonso F. Atrial fibrillation in the elderly. $J$ Geriatr Cardiol. 2019;16(1):49-53. doi:10.11909/j.issn.16715411.2019 .01 .005

20. Banta H, Greenfield J. Left axis deviation. Cardiology EE-AJ of, 1964 undefined. ajconline.org. Available from: https://www.ajcon line.org/article/0002-9149(64)90075-X/pdf. Accessed May 4, 2020.

21. Grant RP. Left axis deviation; an electrocardiographic-pathologic correlation study. Circulation. 1956;14(2):233-249. doi:10.1161/01. CIR.14.2.233

22. Kashou AH, Kashou HE. Electrical axis (normal, right axis deviation, and left axis deviation). StatPearls Publishing; 2018. Available from: http://www.ncbi.nlm.nih.gov/pubmed/29262101. Accessed June 8, 2020.

23. Sachin Khane R, Surdi AD. Gender differences in the prevalence of electrocardiogram abnormalities in the elderly: a population survey in India. Iran J Med Sci. 2012;37(2):92-99.

24. Nielsen JB, Strandberg SE, Pietersen A, Graff C, Holst AG. Left anterior fascicular block and the risk of cardiovascular outcomes. JAMA Intern Med. 2014;174(6):1001-1003. doi:10.1001/ jamainternmed.2014.578

25. Elizari MV, Acunzo RS, Ferreiro M. Hemiblocks: clinic ad epidemiology. Circulation. 2007;115(9):1154-1163. doi:10.1161/ CIRCULATIONAHA.106.637389

26. Elizari MV, Acunzo RS, Ferreiro M. Hemiblocks revisited. Circulation. 2007;115(9):1154-1163. doi:10.1161/CIRCULATIO NAHA.106.637389

27. Kerola T, Eranti A, Aro AL, et al. Risk factors associated with atrioventricular block. JAMA Netw open. 2019;2(5):e194176. doi:10.1001/jamanetworkopen.2019.4176

28. Bussink BE, Holst AG, Jespersen L, Deckers JW, Jensen GB, Prescott E. Right bundle branch block: prevalence, risk factors, and outcome in the general population: results from the Copenhagen City Heart Study. Eur Heart J. 2013;34(2):138-146. doi:10.1093/eurheartj/ehs291

29. Milan A, Puglisi E, Magnino C, et al. Left atrial enlargement in essential hypertension: role in the assessment of subclinical hypertensive heart disease. Blood Press. 2012;21(2):88-96. doi:10.3109/ 08037051.2011.617098

30. Miller JT, O'Rourke RA, Crawford MH. Left atrial enlargement: an early sign of hypertensive heart disease. Am Heart J. 1988;116 (4):1048-1051. doi:10.1016/0002-8703(88)90158-5

31. Vaziri SM, Larson MG, Lauer MS, Benjamin EJ, Levy D. Influence of blood pressure on left atrial size. Hypertension. 1995;25 (6):1155-1160. doi:10.1161/01.HYP.25.6.1155 
32. Gerdts E, Wachtell K, Omvik P, et al. Left atrial size and risk of major cardiovascular events during antihypertensive treatment: losartan intervention for endpoint reduction in hypertension trial. Hypertension. 2007;49(2):311-316. doi:10.1161/01.HYP.00002 54322.96189.85

33. Martinez MA, Sancho T, Armada E, et al. Prevalence of left ventricular hypertrophy in patients with mild hypertension in primary care: impact of echocardiography on cardiovascular risk stratification. $\mathrm{Am}$ $J$ Hypertens. 2003;16(7):556-563. doi:10.1016/S0895-7061(03) 00859-8

34. Akintunde AA, Oyedeji AT, Familoni OB, Ayodele OE, Opadijo OG. QT Interval prolongation and dispersion: epidemiology and clinical correlates in subjects with newly diagnosed systemic hypertension in Nigeria. J Cardiovasc Dis Res. 2012;3(4):290-295. doi:10.4103/ 0975-3583.102705

35. Oikarinen L, Nieminen MS, Viitasalo M, et al. Relation of QT interval and QT dispersion to echocardiographic left ventricular hypertrophy and geometric pattern in hypertensive patients. The LIFE Study. J Hypertens. 2001;19(10):1883-1891. doi:10.1097/ 00004872-200110000-00025
36. Klimas J, Kruzliak P, Rabkin SW. Modulation of the QT interval duration in hypertension with antihypertensive treatment. Hypertens Res. 2015;38(7):447-454. doi:10.1038/hr.2015.30

37. Okin PM, Devereux RB, Nieminen MS, et al. Electrocardiographic strain pattern and prediction of cardiovascular morbidity and mortality in hypertensive patients. Hypertension. 2004;44(1):48-54. doi:10.1161/01.HYP.0000132556.91792.6a

38. Bao H, Cai H, Zhao Y, et al. Nonspecific ST-T changes associated with unsatisfactory blood pressure control among adults with hypertension in China: evidence from the CSPTT study. Med (United States). 2017;96:13. doi:10.1097/MD.0000000000006423

39. Choi HM, Kim HC, Kang DR, Spracklen CN. Sex differences in hypertension prevalence and control: analysis of the 2010-2014 Korea national health and nutrition examination survey. PLoS One. 2017;12(5):e0178334. doi:10.1371/journal.pone.0178334

40. August P. Hypertension in men. J Clin Endocrinol Metab. 1999;84 (10):3451-3454. doi:10.1210/jcem.84.10.6124

41. Mozos I, Caraba A. Electrocardiographic predictors of cardiovascular mortality. Dis Markers. 2015;2015:1-10. doi:10.2147/IJGM.S84537
International Journal of General Medicine

\section{Publish your work in this journal}

The International Journal of General Medicine is an international, peer-reviewed open-access journal that focuses on general and internal medicine, pathogenesis, epidemiology, diagnosis, monitoring and treatment protocols. The journal is characterized by the rapid reporting of reviews, original research and clinical studies across all disease areas. The manuscript management system is completely online and includes a very quick and fair peer-review system, which is all easy to use. Visit http://www.dovepress.com/ testimonials.php to read real quotes from published authors. 